\title{
Plasmodium vivax aldolase-specific monoclonal antibodies and its application in clinical diagnosis of malaria infections in China
}

Emmanuel E Dzakah ${ }^{1,2}$, Keren Kang ${ }^{1,2^{*}}$, Chao $\mathrm{Ni}^{1,2}$, Hong Wang ${ }^{1,2}$, Peidian $\mathrm{Wu}^{2}$, Shixing Tang ${ }^{2}$, Jihua Wang ${ }^{2}$, Jufang Wang ${ }^{1 *}$ and Xiaoning Wang ${ }^{3}$

\begin{abstract}
Background: Most rapid diagnostic tests (RDTs) currently used for malaria diagnosis cannot distinguish the various Plasmodium infections. The development of a Plasmodium vivax specific RDTs with high sensitivity to sufficiently differentiate the two most common Plasmodium infections would be very crucial for disease treatment and control.

Method: Plasmodium vivax aldolase gene (PVALDO) was amplified from the extracted genomic DNA and constructed into pET30a vector. Plasmodium vivax aldolase protein was successfully expressed in Escherichia coli in soluble form and the overall purity was over $95 \%$ after one-step affinity chromatography purification. The purified products were used for the immunization of mice and rabbits. Rabbit polyclonal antibodies generated were deployed to develop a novel antibody-capture ELISA for hybridoma screening.

Results: Three PvALDO specific mAbs (14C7, $15 F 1$ and 5H7) with high affinities were selected and used in immunochromatographic test strips. Clinical blood samples $(n=190)$ collected from Yunnan (China) were used for evaluation and the RDT's sensitivity for P. vivax was $98.33 \%$ (95\% Confidence Interval (Cl): $91.03 \%$ to 99.72\%) compared with microscopic examination. There was specificity of $99.23 \%$ (95\% Cl: $95.77 \%$ to $99.87 \%)$ for $P$. vivax. Only one Plasmodium falciparum sample was detected among the $P$. falciparum samples $(n=20)$. All Plasmodium malariae samples $(n=2)$ as well as healthy uninfected samples $(n=108)$ were negative. Overall performance of this RDT was excellent with positive predictive value (PPV) and negative predictive value (NPV) of 98.33\% and 99.23\%, respectively, at $95 \% \mathrm{Cl}$ and a very good correlation with microscopic observations (kappa value, $\mathrm{K}=0.9757$ ). Test strips show high sensitivity even at $6.25 \mathrm{ng} / \mathrm{ml}$ of recombinant $P$. vivax aldolase (rPvALDO).

Conclusion: This study further elucidates the possibility of developing aldolase-specific RDTs which can differentiate the different Plasmodium infections and improve accurate diagnosis of malaria. This RDT could adequately differentiate between $P$. vivax and $P$. falciparum infections. The novel mAb screening method developed here could find application in the screening of highly specific antibodies against other antigens.
\end{abstract}

Keywords: Plasmodium vivax, Aldolase, Malaria, Monoclonal antibodies, ELISA

\footnotetext{
* Correspondence: jufwang@scut.edu.cn; keren_kang@wondfo.com.cn ${ }^{1}$ School of Bioscience and Bioengineering, South China University of Technology, University City, Panyu District, Guangzhou 510006, China

${ }^{2}$ National Engineering Laboratory of Rapid Diagnostic Tests, Guangzhou Wondfo Biotech Co., Ltd, Science City, Lizhishan Rd. No. 8Luogang District, Guangzhou 510663, China

Full list of author information is available at the end of the article
} 


\section{Background}

Plasmodium vivax, a causative agent of relapsing benign tertian malaria, is the second most important malaria causing species and afflicts several hundred million people every year $[1,2]$. The occurrence rate of $P$. vivax infection ranges between $70-90 \%$ in most of Asia and South America, 50-60\% in South Eastern Asia and Western Pacific, and 1-10\% in Africa [3].

Rapid and effective diagnosis of the disease is essential for combating and eradicating malaria in the world. Microscopic examination of thick and thin blood smears from patients have served as the gold standard in diagnosing malaria over the years [4]. However, the greater section of those patients affected by malaria reside in villages and the very remotes areas of the world, making trained personnel, microscopes and other equipment difficult to access. These shortcomings have necessitated the emergence of rapid diagnostic tests (RDTs). These tests are effective, quick and easy to use after short appropriate training. Until now, many RDTs have been developed with great focus on the detection of histidine-rich protein 2 (HRP-2) from Plasmodium falciparum and parasite specific lactate dehydrogenase $(\mathrm{pLDH})$ or Plasmodium aldolase from all species [4]. Nevertheless, most of these RDTs have reported undesirably low sensitivities for the diagnosis of $P$. vivax [5] and are unable to correctly distinguish between $P$. vivax, $P$. falciparum or mixed infections, a situation that has adverse effects on the accurate treatment of the disease.

Aldolase is a major enzyme involved in the glycolytic cycle of Plasmodium and is released into the blood during infection or can be localized in the cytoplasm of the parasite in soluble forms [6]. Plasmodium falciparum and P. vivax possess only one aldolase isoenzyme [5,7], and a high proportion of the amino acid sequences are relatively conserved in all Plasmodium species [8,9], making aldolase a pan-specific target antigen for Plasmodium detection. The $P$. vivax aldolase gene has 1100 base pairs which are translated into 369 amino acids with a molecular weight of $41 \mathrm{KDa}$.

In this paper, the cloning and expression of soluble $P$. vivax aldolase proteins in Escherichia coli and the development of novel monoclonal antibody (mAb) screening methods for selecting high affinity antibodies is described. MAbs specific to the $P$. vivax aldolase were utilized in immunochromatographic tests for screening of clinical blood samples. This opens the door to the production of $P$. vivax specific RDTs that target the aldolase antigen and can therefore used as an alternative to augment the already existing malaria RDTs.

\section{Methods \\ Materials}

Restriction endonucleases, NdeI and SalI, and PrimeStar Hs mix, and PCR mix, DNA markers were purchased from TaKaRa Biotech Company (Dalian, China). pET-30a plasmid, competent E. coli cells (DH5 $\alpha$ and BL21 (DE3)) and SP2/0-Ag14 myeloma cells were preserved in School of Bioscience and Bioengineering, South China University of Technology (China). RPMI 1640 medium, fetal bovine serum (FBS), kanamycin, penicillin-streptomycin, hypoxanthine and thymidine (HT), hypoxanthineaminopterin-thymidine medium (HAT) and polyethylene glycol (PEG) were purchased from Gibco (California, U.S.A). Methyl cellulose was purchased from SigmaAldrich (St. Louis, U.S.A). All chemicals used were of higher molecular grade.

\section{Samples collection and examination}

Field and clinical blood samples of $P$. vivax $(\mathrm{n}=60)$ and $P$. falciparum $(\mathrm{n}=20)$ from infected persons and normal blood from healthy uninfected individuals $(n=108)$ were collected from the Yunnan Province, China. Plasmodium malariae samples $(n=2)$ were supplied by the Yunnan Institute of Parasitic Research, China. All samples were read by two experienced microscopists. Giemsa-stained thick blood smears were examined by light microscopy for 100 thick-film fields. Parasite species and density in positive films were identified and recorded as the number of parasites per 200 white blood cells.

\section{PCR cloning and recombinant protein expression}

Total genomic DNA was extracted from infected blood using Animal Genomic DNA Mini Preparation Extraction Kit purchased from New Probe Biotech Company (Beijing, China). A pair of oligonucleotide primers were designed, complementary to the forward and reverse strands of the PvALDO (aldolase) gene based on the putative sequence of $P$. vivax isolate KPValdo06-43 obtained from GenBank (Accession number: HQ230241.1). The forward primer, PV-ALD-F, '5-GACTCATATGGCCACTGGATCCGAA TA-'3, and the reverse primer, PV-ALD-R, '5-TACA GTCGACATAGACGTACTTCTTTTCGTAAG-'3 were designed to contain the NdeI and SalI restriction sites, respectively. Electrophoresis of the PCR product on a $1 \%$ agarose gel gave a DNA band of the expected size which was excised and purified. The purified PCR product and the pET30a vector were double digested with NdeI and SalI restriction enzymes and cloned into $\mathrm{pET} 30$ a vector.

The pET-30a plasmid containing the PvALDO gene was transformed into $\mathrm{CaCl}_{2}$ competent $E$. coli BL21 (DE3) cells. The transformed cells were verified by colony PCR. For small scale protein expression, starter cultures were grown overnight at of $37^{\circ} \mathrm{C}$ in $5 \mathrm{ml} \mathrm{LB}$ medium, supplemented with $50 \mathrm{mgml}^{-1}$ kanamycin. About $100 \mu \mathrm{l}$ of saturated overnight cultures were used to inoculate $10 \mathrm{ml}$ cultures and then allowed to grow to OD 600 between $0.6-0.8$ at $37^{\circ} \mathrm{C}$ before protein induction with $1 \mathrm{mM}$ IPTG. Cultures were incubated at different 
temperatures of $30^{\circ} \mathrm{C}$, in a shaker with and without induction with IPTG for $4 \mathrm{~h}$. The cells were harvested by centrifugation at $6,000 \times \mathrm{g}$ for $10 \mathrm{~min}$. The cell supernatant was removed and the cell pellet was re suspended in lysis buffer consisting of 100 mM Tris$\mathrm{HCl}, \mathrm{pH}$ 8.8. Cell suspensions were disintegrated ultrasonically on ice and centrifuged at $6,000 \times \mathrm{g}$ for 15 min. The protein content of the supernatant and pellet fractions were visualized on 12\% SDS PAGE. Recombinant $P$. vivax aldolase (rPvALDO) protein was purified on a HiTrap $\mathrm{Ni}^{2+}$ column using AKTA Purifier (GE Healthcare, UK). The resulting pure protein ( $>95 \%$ purity) was buffer exchanged and stored at $-20^{\circ} \mathrm{C}$ until immunization.

\section{Western blot analysis}

SDS-PAGE was carried out on $12 \%$ separating and $5 \%$ stacking gels using the Laemmli discontinuous buffer system [10]. Samples were boiled for 5 min with SDS loading buffer prior to loading and then electrophoresed. Proteins were transferred to a polyvinylidene fluoride (PVDF) membrane in transfer buffer (25 mM Tris, 186 $\mathrm{mM}$ glycine, and 20\% methanol). After blocking with 5\% non-fat milk in $1 \mathrm{X}$ Tris-buffered saline (TBS) supplemented with $0.1 \%$ Tween-20, $\mathrm{pH} 7.4$ for $2 \mathrm{~h}$ at room temperature, the membrane was then incubated in 1:2,000 anti-6X His tag antibody (Abcam, Cambridge, UK) for $2 \mathrm{~h}$ at room temperature. Membranes were washed in three changes of TBS-T. PvALDO proteins were visualized with Supersignal West Pico chemiluminescent substrate kit (Thermo Fisher Scientific Inc., Rockford, USA) and scanned with MicroChemi Western Blot Analyser (DNR Bio-Imaging Systems Ltd, Israel).

\section{Monoclonal and polyclonal antibody production Animal immunization}

Six-to-eight-week-old Balb/c mice purchased from Guangdong Animal Laboratory Center (Guangzhou, China), were injected subcutaneously with $100 \mu \mathrm{g}$ of the purified rPvALDO protein in equal portion of complete Freund's adjuvant (CFA), (Sigma, St. Louis, U.S.A), for the initial immunization. Three booster immunizations were done at two-week intervals with $50 \mu$ g protein in incomplete Freund's adjuvant (IFA). The mice received a final booster injection with $100 \mu \mathrm{g}$ protein intraperitoneally three days prior to cell fusion. A three-month old female rabbit of $2.5 \mathrm{~kg}$ was immunized with $1 \mathrm{ml}$ of rPvALDO-saline-adjuvant mixture containing $800 \mu \mathrm{g}$ antigen for the initial immunization and $500 \mu \mathrm{g}$ in three subsequent boosters at two-week intervals. This research does not violate any national guidelines and institutional policies for use of animals in research.

\section{Polyclonal antibody purification and conjugation by periodate method}

Blood $(10 \mathrm{ml})$ was collected from the central vein of the rabbit and allowed to clot at room temperature for $2 \mathrm{~h}$, incubated at $4^{\circ} \mathrm{C}$ for $2 \mathrm{~h}$ and then centrifuged at $6,000 \times \mathrm{g}$ for 15 mins. Serum was purified by caprylic acid and ammonium sulfate precipitation. The purified rabbit anti-aldolase IgG $(1 \mathrm{mg})$ was labelled with horseradish peroxidase (HRP) by oxidation method [11]. The produced conjugates were tested by indirect ELISA method.

\section{Hybridoma production and mAbs generation}

Mice were sacrificed and the spleen cells were fused with the myeloma cell line SP2/0-Ag14 at a ratio of 10:1 using PEG 1500 as described by Kohler and Milstein [12]. The fused cells were then mixed with methylcellulose-RPMI 1640 media supplemented with $15 \%$ (v/v) FBS, $100 \mathrm{U} / \mathrm{mL}$ penicillin, $100 \mu \mathrm{g} / \mathrm{mL}$ streptomycin, $1 \%$ (v/v) HEPES, 2\% (w/v) methyl cellulose, 1\% (v/v) HAT) (Gibco, California, U.S.A), and plated on petri dishes $(35 \mathrm{~mm})$. The dishes were incubated at $37^{\circ} \mathrm{C}$ under a $5 \% \mathrm{CO}_{2}$ overlay for 57 days in humidified chambers. Fast growing hybridoma clones were picked into 96-well plates containing complete RPMI 1640 medium supplemented with $1 \%$ HT. Cell culture supernatants were screened using both indirect and a novel antibody-capture ELISA described below.

\section{Enzyme-linked immunosorbent assays}

Both the indirect ELISA assay and a novel antibodycapture ELISA screening methods were used in the selection of hybridomas that produce antibodies against the rPvALDO antigen. In the indirect method, the wells of microtitre plates were coated with $2 \mu \mathrm{g} / \mathrm{ml}$ of rPvALDO antigen in coating buffer ( $0.05 \mathrm{M}$ carbonate buffer, $\mathrm{pH}$ 9.6) for $3 \mathrm{~h}$. The plates were washed $(0.015 \mathrm{M}$ phosphate buffered saline (PBS) with $0.1 \%$ Tween 20) and blocked with 3\% BSA for $2 \mathrm{~h}$ before the addition of $100 \mu \mathrm{l}$ of cell culture supernatant for $1 \mathrm{~h}$ at $37^{\circ} \mathrm{C}$. HRP conjugated goat anti-mouse IgG (ZSGB-BIO, Beijing, China) at 1:20,000 dilution was added to each well and incubated for 30 mins. The plates were then washed and enzymatic reaction was visualized using substrate TMB with hydrogen peroxide and stopped with $2 \mathrm{M}$ sulphuric acid. Optical density was measured by spectrophotometer at wavelength of $450 \mathrm{~nm}$.

In the novel antibody-capture ELISA method, the microtitre plates were coated with goat-anti-mouse IgG (GAM) at $2 \mu \mathrm{g} / \mathrm{ml}$ and incubated at $4{ }^{\circ} \mathrm{C}$ overnight. After rinsing, the plates were blocked with 3\% BSA for $2 \mathrm{hr}$. $100 \mu \mathrm{l}$ cell supernatant was added to each well and incubated for $1 \mathrm{hr}$. Plates were washed and the rPvALDO antigen $(2 \mu \mathrm{g} / \mathrm{ml})$ was added and incubated for another 
30 mins. After rinsing, $100 \mu \mathrm{l}$ rabbit-anti-PvALDO IgGHRP $(1: 5,000)$ diluted in $1 \%$ BSA containing $1 \%$ healthy mouse serum was dispensed into each well and incubated for 30 mins at $37^{\circ} \mathrm{C}$ and then rinsed. Enzymatic reaction was visualized as described above.

\section{Ascites production and purification}

Two adult F1 hybrid mice (Animal Laboratory, SunYat-Sen University, Guangzhou, China) were injected intraperitoneally with mineral oil $(0.5 \mathrm{ml} /$ mouse) followed by injection with $5 \times 10^{6}$ of hybridoma cells on the seventh day. Ten days later, ascites were collected and centrifuged at $6,000 \times \mathrm{g}$ for $10 \mathrm{~min}$. The IgG fractions were prepared by ammonium sulfate precipitation followed by purification on Protein A column. The titer of both ascites and purified mAbs were determined by antibody-capture ELISA.

\section{Isotyping and affinity of $m A$ s s}

Commercial ISO-2 kit (Sigma, St. Louis, USA) was used in the determination of the isotypes of the monoclonal antibodies. Antibody affinity was determined and calculated as described by Raghava and Agrewala with little modifications [13]. Polystyrene 96-well plates were coated with GAM and serial dilutions $(1.25 \mu \mathrm{g} / \mathrm{ml}$ to 0$)$ of $\mathrm{mAbs}$ were added and incubated for $1 \mathrm{~h}$. Serially diluted antigen concentrations $(0.50,0.25,0.125,0.0625$ $\mu \mathrm{g} / \mathrm{ml}$ ) were then added for 30 mins. After rinsing, rabbit anti-ALDO IgG-HRP $(1: 20,000)$ was added and incubated for 30 mins at $37^{\circ} \mathrm{C}$. Colour development was measured at $450 \mathrm{~nm}$ on a microtitre plate reader.

\section{Immunochromatographic test strips for the evaluation of clinical samples}

Monoclonal antibodies $15 \mathrm{~F} 1$ and $5 \mathrm{H} 7$ were used as capture and labelled antibodies respectively in an immunochromatographic assay. The $5 \mathrm{H} 7$ antibody was conjugated to colloidal gold and sprayed on glass fiber at $12 \mu \mathrm{cm}^{-2}$. Monoclonal antibody $15 \mathrm{~F} 1(2.0 \mathrm{mg} / \mathrm{ml})$ and goat-anti-mouse IgG $(1.0 \mathrm{mg} / \mathrm{ml})$ were sprayed on a nitrocellulose membrane at 1.5 and $1 \mu \mathrm{cm}^{-1}$ to form the test and control lines respectively. The glass fiber pad and the membrane were left to dry at $30^{\circ} \mathrm{C}$ overnight. During the assembly of the test kit, $0.6 \mathrm{~cm}$ of the colloidal gold labelled $\mathrm{mAb} 5 \mathrm{H} 7$ glass fiber was placed a few centimeters away from the mAb 5F1 test line with an absorption pad placed at the opposite end. The assembly was cut into $3.0 \mathrm{~mm}$ wide strips. A maximum of $5 \mu \mathrm{l}$ blood was applied to the sample application site and a sample dilution buffer was added and the colour development observed for 15 mins. A red band in the test and control line zones is formed for positive samples and the absence of a band in the test line zone is indicative of negative results while test samples without the appearance of the controls are regarded invalid and, therefore, repeated. False positive or negative results are cross examined by PCR.

\section{Test strip sensitivity to recombinant aldolase}

Serial dilutions of rPvALDO $(100 \mathrm{ng} / \mathrm{ml}, 50 \mathrm{ng} \mathrm{ml}, 25$ $\mathrm{ng} / \mathrm{ml}, 12.5 \mathrm{ng} / \mathrm{ml}, 6.25 \mathrm{ng} / \mathrm{ml}, 3.125 \mathrm{ng} / \mathrm{ml}, 1.56 \mathrm{ng} / \mathrm{ml}$, and $0.78 \mathrm{ng} / \mathrm{ml}$ ) were applied to the test strips to check its sensitivity level at different antigen concentrations. Strips were observed for a maximum of 15 mins and the colour development was compared with a standard colour chart and the band intensity graded.

\section{Data analysis}

The sensitivity and specificity of the immuno chromatographic assay for the detection of $P$. vivax were compared with thick blood microscopic examination results by Kappa statistical analysis, K [14]. $\mathrm{P}<0.005$ was considered as significant.

\section{Results}

\section{Cloning and expression of recombinant protein}

The total Plasmodium genomic DNA from P. vivax infected blood was extracted with a concentration of 16.2 $\mu \mathrm{g} / \mathrm{ml}$. Two oligo primers were designed and modified to contain the NdeI and SalI restriction sites. Amplification

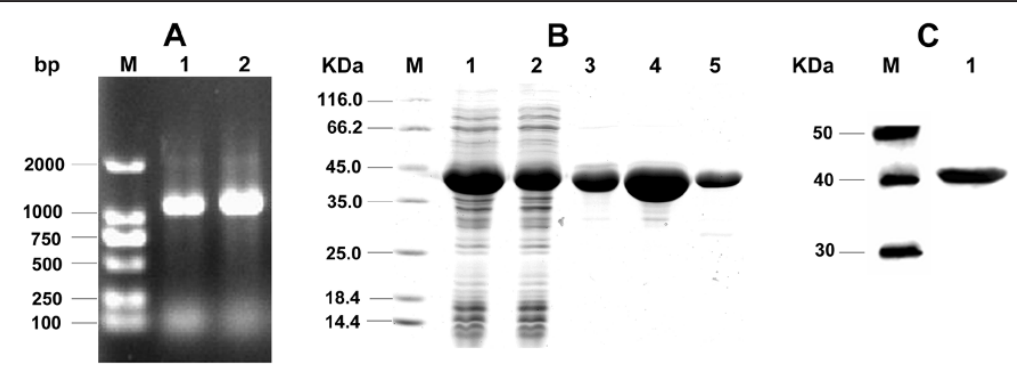

Figure 1 Gene amplification and protein expression. (A) PCR of PVALDO gene. M: DL2000 marker, 1 and 2 represent annealing temperatures $50.4^{\circ} \mathrm{C}$ and $52.4^{\circ} \mathrm{C}$, respectively. (B) Protein expression and purification. M: Marker, lanes 1 and 2 are the whole cell lysate and supernatant after induction, respectively. Lanes 3, 4 and 5 are pooled portions of purified products. (C) Western blot analysis of PvALDO protein. M: Marker, 1: Purified PvALDO protein $(10 \mu \mathrm{g})$. 


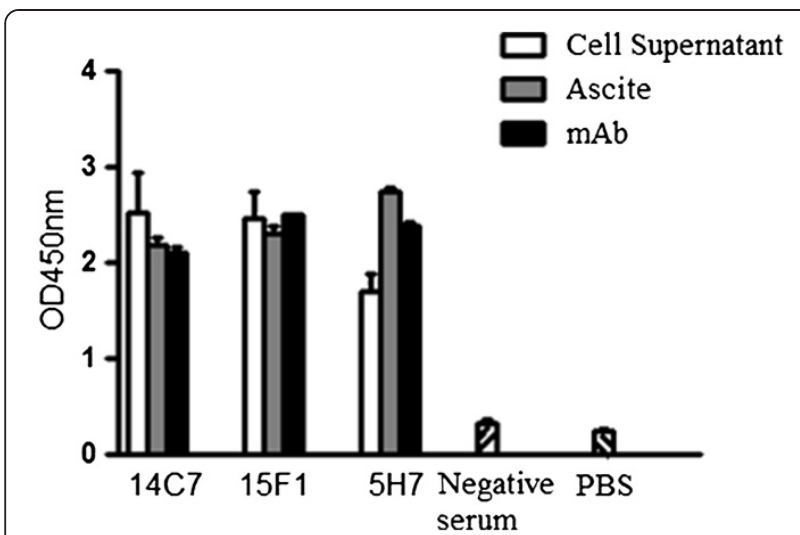

Figure 2 Antibody titer of cell supernatants, ascites and purified antibodies. The OD values (mean $\pm \mathrm{SD}$ ) of hybridoma cell supernatants, ascites ( $10^{-3}$ dilution), and mAbs $(1 \mathrm{\mu g} / \mathrm{ml})$ were measured by the antibody-capture ELISA at $450 \mathrm{~nm}$. Polystyrene 96well plates were coated with GAM $(2 \mu \mathrm{g} / \mathrm{ml})$, antibodies were added and rPVALDO used was at a concentration of $2 \mu \mathrm{g} / \mathrm{ml}$ and HRP conjugated rabbit-anti-ALD IgG (1:5000) was used as secondary antibody. PBS and normal mouse serum were used as control.

of the full-length PvALDO gene was carried out and the expected DNA band size of $1.1 \mathrm{~Kb}$ was observed (Figure 1A). The PCR product and pET30a vector plasmid were digested with NdeI and SalI restriction enzymes, purified and ligated together. Ligation products were used to successfully transform competent BL21 (DE3) E. coli cells. Analysis of the cell pellets and supernatant by SDS PAGE after induction revealed over-production of the target protein with molecular weight of $41 \mathrm{kDa}$ in the pellet for cells cultured at $37^{\circ} \mathrm{C}$. Reducing the incubation temperature to $30^{\circ} \mathrm{C}$ showed marked expression of soluble proteins in the supernatant (Figure 1B). It was however observed that higher incubation temperatures result in the formation

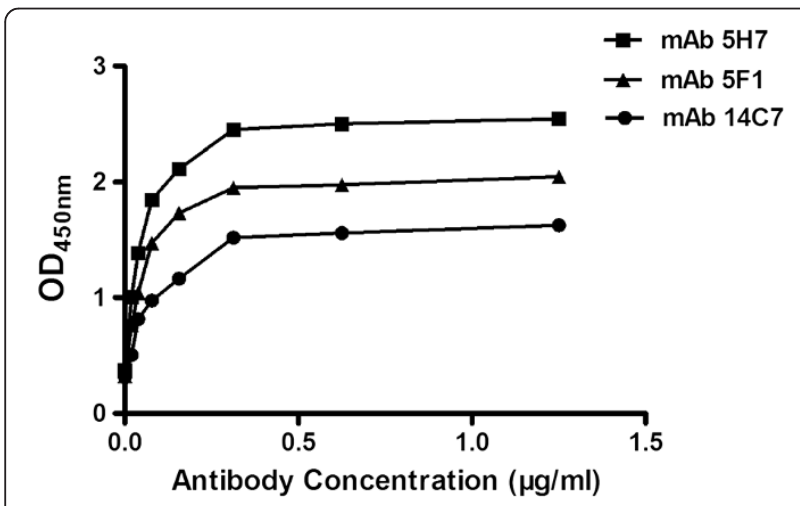

Figure 3 Antibody affinity. Plates were coated with GAM (2 $\mu \mathrm{g} /$ $\mathrm{ml}$ ) and $\mathrm{mAbs} 14 \mathrm{C} 7,15 \mathrm{~F} 1$ and $5 \mathrm{H} 7$ at concentrations of $1.25,0.63$, $0.313,0.156,0.078,0.039$ and $0.01953 \mu \mathrm{g} / \mathrm{ml}$ were added for $1 \mathrm{~h}$. rPvALDO $(0.5 \mu \mathrm{g} / \mathrm{ml})$ was added and PBST was used as negative control. Rabbit-anti-ALD IgG-HRP (1:5000) was used as secondary antibody.
Table 1 Comparison between indirect and novel Ab capture methods

\begin{tabular}{ccc}
\hline mAb & \multicolumn{2}{c}{ Antibody screening method } \\
\hline & Indirect ELISA & Novel antibody capture ELISA \\
$5 \mathrm{H} 7$ & 1.921 & 2.273 \\
$14 \mathrm{C7}$ & 1.544 & 1.475 \\
$15 \mathrm{~F} 1$ & 0.28 & 1.907 \\
Negative control & 0.09 & 0.105 \\
\hline
\end{tabular}

of inclusion bodies. Expression was then carried out at $30^{\circ} \mathrm{C}$ and purified on a HiTrap $\mathrm{Ni}^{2+}$ column with a total a purity of $>95 \%$ (Figure 1B). Western blot analysis of the protein using rabbit-anti-His antibodies revealed the intact integrity of the protein (Figure 1C).

\section{Animal immunization}

The sera of immunized mice showed high antibody titers after the second booster immunization. Relatively good titers were observed at $10^{-5}$ dilutions. Purified rabbit sera also showed very high antibody titers after the third booster immunization with titers still high at $10^{-6}$ dilution.

\section{Antibody titer and affinity}

The antibody titers of the three selected mAbs (14C7, 15F1 and 5H7) were high in cell culture medium, ascite and after Protein A purification (Figure 2). The affinity of these mAbs for rPvALDO was also determined at different antigen and antibody concentrations. Computed affinities were $1.69 \times 10^{6}, 2.36 \times 10^{7}$, and $2.24 \times 10^{6} \mathrm{M}^{-1}$ for $14 \mathrm{C} 7,15 \mathrm{~F} 1$ and $5 \mathrm{H} 7$, respectively (Figure 3 ).

\section{Comparison between indirect and novel antibody capture ELISA}

The novel antibody capture ELISA proves to be more reliable in the screening of hybridoma clones. Clone $15 \mathrm{~F} 1$ which was undetected by indirect ELISA due to extremely low optical density was easily identified using this method of screening (Table 1).

\section{Characteristics of anti-PvALDO mAbs}

Commercial ISO-2 kit was used in the determination of the isotypes of the mAbs. The isotype, purity and concentration of the purified antibodies are presented in Table 2.

Table 2 Characteristics of anti-PvALDO mAbs

\begin{tabular}{cccc}
\hline mAb & Isotype & Purity (\%) & Concentration $(\mathbf{m g} / \mathbf{m l})$ \\
\hline $5 H 7$ & $\lg G 1$ & 90 & 4.02 \\
$14 C 7$ & $\lg G 1$ & 85 & 2.56 \\
$15 \mathrm{~F} 1$ & $\operatorname{lgG} 1$ & 80 & 3.30 \\
\hline
\end{tabular}


Test strip sensitivity to recombinant aldolase antigen

Different combinations of mAbs 14C7, 15F1 and 5H7 as either capture or detector antibody showed that all three mAbs could be used for the establishment of immunochromatographic assays. However, the 15F1-5H7 format, that showed the best sensitivity, was selected for further experimentation. The sensitivity of the test strips were determined by treatment with different antigen concentrations $(100 \mathrm{ng} / \mathrm{ml}, 50 \mathrm{ng} / \mathrm{ml}, 25 \mathrm{ng} /$ $\mathrm{ml}, 12.5 \mathrm{ng} / \mathrm{ml}, 6.25 \mathrm{ng} / \mathrm{ml}, 3.12 \mathrm{ng} / \mathrm{ml}, 1.56 \mathrm{ng} / \mathrm{ml}$, and $0.78 \mathrm{ng} / \mathrm{ml}$ ) and the band intensity was observed after 15 mins and compared with standard colour chart. Good assay sensitivity was observed up to 6.25 $\mathrm{ng} / \mathrm{ml}$ of antigen (Figure 4).

\section{Comparison of immunochromatographic test strips and standard method}

Test strips were used to evaluate $P$. vivax positive samples $(n=60)$, of which 59 positives $(59 / 60)$ and one false negative $(1 / 60)$ was detected. Negative results were observed in all non-P. vivax samples (129/130), except for one $P$. falciparum sample that was positive for both test strip and PCR cross examination. The parasitaemia density of this sample was 4,560 parasites/ $\mu$ l and even at this density, the positive line was extremely faint and hardly visible to the naked eye. All serial dilutions testing of this $P$. falciparum sample were negative. All $P$. malariae samples $(\mathrm{n}=2)$ were negative (Table 3$)$. Agreement between the immunochromatographic test strips and thick blood smear reference method for the 190 whole blood samples were analysed (Table 4). The specificity and sensitivity of these test strips, compared with microscopic examination were 99.23\% (95\% Confidence Interval (CI): $95.77 \%$ to $99.87 \%$ ) and $98.33 \%$ 95\% CI: $91.03 \%$ to $99.72 \%$, respectively. Positive predictive value (PPV) and negative predictive value (NPV) of 98.33\% and $99.23 \%$ respectively were also observed at $95 \%$ confidence interval. There was also a strong agreement $(\mathrm{K}=$ 0.9757 ) between the immunochromatographic test strips and the standard method.

\section{Discussion}

Malaria is still one of the world's most deadly diseases today despite the huge investment in combating the disease. Although $P$. falciparum is the most lethal of all Plasmodium species, P. vivax is the most widespread and common and thus, responsible for the greatest burden of the disease outside Africa $[1,15]$ and results in close to more than half of the worldwide malaria cases [16]. According to $\mathrm{WHO}$, product testing has shown remarkable improvement in test quality over time, and more high quality tests are being procured over time [17]. Although there is significant improvement in the quality of these assays, only a few that target malaria parasite antigens have really worked to expectation. The major malaria antigens targeted by these RDTs are $P$. falciparum specific HRP-2, pLDH and pan-specific aldolase. The ability of these assays to differentiate the various Plasmodium forms is another difficulty. It is, therefore, prudent to develop monoclonal antibodies that can sufficiently differentiate the two most common Plasmodium species, P.vivax and P. falciparum.

The high homology among the Plasmodium species confirmed the assertion that many regions in Plasmodium aldolase gene are completely or highly conserved [9]. These regions may contribute to determining the authentic common antigenic epitopes among these strains of malaria parasite which can assist in the development of drugs targeting these sites. This common epitopes can be exploited for the development of pan-specific mAbs against Plasmodium species. In this study, the cloning and expression of soluble recombinant $P$.

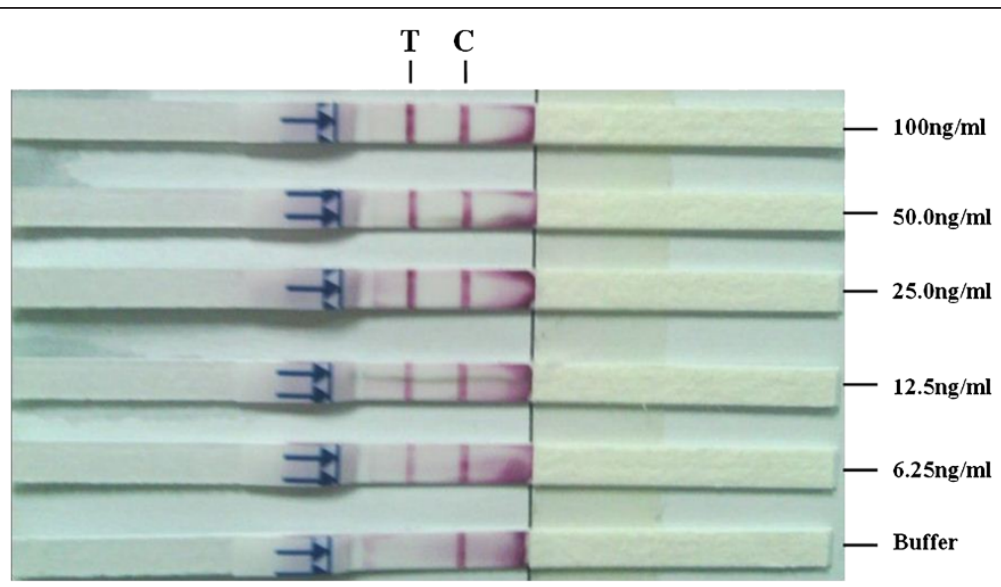

Figure 4 Sensitivity of assay to rPvALDO antigen. Test strips were treated with different concentrations of rPvALDO antigen and the colour development observed after 15 mins. T and $\mathrm{C}$ represent the test and control lines, respectively. 
Table 3 Band intensities of immunochromatographic test strips.

\begin{tabular}{|c|c|c|c|c|c|c|}
\hline \multirow[b]{2}{*}{ Plasmodium spp. (density) } & \multicolumn{6}{|c|}{ Detection level* } \\
\hline & Negative & Faint & Weak & Medium & Strong & Total \\
\hline P. vivax $(1-499 / \mu l)$ & 1 & 9 & 5 & & & 15 \\
\hline P. vivax (500-1000 $\mu \mathrm{l})$ & & & 7 & 10 & & 17 \\
\hline P. $\operatorname{vivax}(>1000 \mu \mathrm{l})$ & & & 5 & 18 & 5 & 28 \\
\hline P. falciparum & 19 & 1 & & & & 20 \\
\hline P. malariae & 2 & & & & & 2 \\
\hline Healthy uninfected persons & 108 & & & & & 108 \\
\hline Total & 130 & 10 & 17 & 28 & 5 & 190 \\
\hline
\end{tabular}

*Detection level: Band intensity as read independently by two readers.

Microscopic smear examinations served as standard reference.

vivax specific aldolase antigen and its application in the production of high affinity mAbs for malaria diagnosis is described.

The recombinant antigen was used in immunizing rabbit and mice for the production of polyclonal and monoclonal antibodies respectively. The high titers observed in all immunized animals after the second booster immunization are an indication of the immunogenicity of the recombinant protein. Rabbit anti-PvALDO polyclonal antibodies were used in a novel antibody-capture ELISA for the screening of $P$. vivax specific mAbs. With this screening model, it is possible to screen out very good antibodies that could probably not be detected by the traditional indirect ELISA used by most researchers for hybridoma screening. Three mAbs 14C7, 15F1 and 5H7 were selected after a number of sub-cloning and limiting dilutions. mAb 15F1 had extremely low titer when indirect ELISA was used for antibody screening, but very good titer value with the newly developed antibody-capture method. This means that mAbs with similar characteristics have a greater probability of being rejected when applying the traditional indirect ELISA method of hybridoma screening (Table 1). The reason for this phenomenon is unknown but might probably have been due to overshadowing of the epitopes of the antigen during coating. Selected mAbs were used in the establishment of immunochromatographic test strips for evaluation of assay sensitivity and specificity. All antibodies were of the IgG1 class (Table 2). mAbs 15F1 and 5H7 could favourably pair-up as capture and detection antibodies respectively in immunochromatographic assay for the detection of both recombinant and native aldolase in human blood samples.

Plasmodium vivax positive samples $(\mathrm{n}=60)$, P. falciparum positive samples with no mixed infections $(n=20)$, $P$. malariae samples $(\mathrm{n}=2)$ and healthy uninfected blood samples $(n=108)$ were evaluated with the immunochromatographic test strips versus microscopic examination. Among the 60 P. vivax samples, one false negative was observed for samples with parasite densities $<500$ parasites/ $\mu$ l (Table 3 ). This false negative $P$. vivax sample had a parasitaemia density of 54 parasites/ $\mu$ l. The extremely low level of parasitaemia might have accounted for the inability of the test strip to detect this blood samples. The other $59 \mathrm{P}$. vivax positive samples had parasitaemia density range between 120 to 14,220 parasites $/ \mu \mathrm{l}$. This result indicates that samples with parasitaemia below a detectable range of about 100 parasites/ $\mu \mathrm{l}$ are very likely to be undetected. The disparity in the level of sensitivity of the test strip to actively circulating $P$. vivax blood aldolase antigen and its recombinant form might probably be due to the a stronger affinity of these antibodies to the active enzyme. Overall sensitivity and specificity of the immunochromatographic assay were $98.33 \%(59 / 60)$ and $99.23 \%(129 / 130)$, respectively at a 95\% CI and Kappa statistics of 0.9757, P<0.005 (Table 4), an indication of a strong agreement between this test and standard methods used in malaria diagnosis. The only observed false positive sample was a $P$. falciparum infected patient that might have been infected with both strains of the parasite. Plasmodium malariae samples were also negative. This assay showed high specificity for the $P$. vivax aldolase and not the $P$. falciparum or human blood forms. Because of the scarcity and the difficulty in obtaining the other Plasmodium species ( $P$. ovale, $P$. knowlesi), only the $P$. vivax, $P$. falciparum and $P$. malariae were tested. The high sensitivity and specificity observed in this assay makes it a favourable alternative to the low sensitivities observed in other commercial RDTs in the detection of $P$. vivax [5]. Previous studies have also observed decreased levels of sensitivity in pLDH-specific RTDs for non-P. falciparum (P. vivax) at parasite densities above

\begin{tabular}{|c|c|c|c|c|}
\hline & Positive & Negative & Total & Kappa, K* \\
\hline Positive & 59 & 1 & 60 & 0.9757 \\
\hline Negative & 1 & 129 & 130 & \\
\hline Total & 60 & 130 & 190 & \\
\hline
\end{tabular}

*A strong agreement was observed at $\mathrm{K}=0.9757(\mathrm{P}<0.005)$. 
5,000 parasites $/ \mu \mathrm{l}$ and higher rate of false negative results in $P$. vivax infections $[18,19]$.

\section{Conclusion}

In conclusion, results from our current evaluation showed that these PvALDO test strips have good specificity and sensitivity for $P$. vivax even at very low parasite densities, it would hence be expedient to further explore these antibodies in a larger population for use as diagnostic tools for rapid and convenient clinical assessment of suspected malaria infections caused by $P$. vivax. An added advantage of this assay would be its ability to adequately differentiate the two most important Plasmodium forms ( $P$. falciparum and $P$. vivax), a decision that is very critical in the therapeutic treatment of malaria.

\section{Competing interests}

The authors declare that they have no competing interests.

\section{Authors' contributions}

EED and KK performed the experiments. CN and HW assisted in the protein expression. PW assisted in immunization and hybridoma screening. KK also carried out samples collection and organized the microscopic diagnosis. ST, JW, JW and XW were responsible for the design and application of the study. All authors read and approved the final manuscript.

\section{Acknowledgement}

The authors wish to thank Prof. Hui Liu of Yunnan Provincial Institute of Parasitic Diseases, for the provision of clinical samples used in DNA extraction and test strip evaluation. This work was financially supported by Program for New Century Excellent Talents in University (NCET-10-0399), the Scientific and Technological Specialized Project for the National New Medicine Formulation (2011ZX09506-001), and Special-funded Program on National Key Scientific Instruments and Equipment Development (2011YQ030139).

\section{Author details}

${ }^{1}$ School of Bioscience and Bioengineering, South China University of Technology, University City, Panyu District, Guangzhou 510006, China. ${ }^{2}$ National Engineering Laboratory of Rapid Diagnostic Tests, Guangzhou Wondfo Biotech Co., Ltd, Science City, Lizhishan Rd. No. 8Luogang District, Guangzhou 510663, China. ${ }^{3}$ Institute of Life Science, General Hospital of Chinese People's Liberation Army, Beijing 100853, China.

Received: 17 January 2013 Accepted: 4 June 2013

Published: 12 June 2013

\section{References}

1. Mendis K, Sina BJ, Marchesini P, Carter R: The neglected burden of Plasmodium vivax malaria. AmJTrop Med Hyg 2001, 64:97-106.

2. Gething PW, Elyazar IR, Moyes CL, Smith DL, Battle KE, Guerra CA, Patil AP, Tatem AJ, Howes RE, Myers MF, George DB, Horby P, Wertheim HF, Price RN, Müeller I, Baird JK, Hay Sl: A long neglected world malaria map: Plasmodium vivax endemicity in 2010. PLoS Negl Trop Dis 2012, 6:e1814.

3. Malaria Site: The Malaria Parasites. www.malariasite.com/malaria/ MalarialParasite.htm\#P. vivax.

4. Moody A: Rapid diagnostic tests for malaria parasites. Clin Microbiol Rev 2002, 15:66-78.

5. Tjitra E, Suprianto S, Dyer M, Currie BJ, Anstey NM: Field evaluation of the ICT malaria Pf/Pv immunochromatographic test for detection of Plasmodium falciparum and Plasmodium vivax in patients with presumptive clinical diagnosis of malaria in eastern Indonesia. J Clin Microbiol 1999, 37:2412-2417.

6. Knapp B, Hundt E, Küpper HA: Plasmodium falciparum aldolase: gene structure and localization. Mol Biochem Parasitol 1990, 40:1-12. doi:10.1016/0166-6851(90)90074-V.
7. Cloonan N, Fischer K, Cheng Q, Saul A: Aldolase genes of Plasmodium species. Mol Biochem Parasitol 2001, 113:327-330.

8. Kim H, Certa U, Döbeli H, Jakob P, Hol WG: Crystal structure of fructose-1, 6-bisphosphate aldolase from the human malaria parasite Plasmodium falciparum. Biochemistry 1998, 37:4388-4396.

9. Lee N, Baker J, Bell D, McCarthy J, Cheng Q: Assessing the genetic diversity of the aldolase genes of Plasmodium falciparum and Plasmodium vivax and its potential effect on the performance of aldolase detecting Rapid Diagnostic Tests (RDTs). J Clin Microbiol 2006, 44:4547-4549. doi:10.1128/JCM.01611-06.

10. Laemmli UK: Cleavage of structural proteins during the assembly of the head of bacteriophage T4. Nature 1970, 227:680-685.

11. Farr AG, Nakane PK: Immunohistochemistry with enzyme labeled antibodies - a brief review. J Immunol Methods 1981, 47:129-144.

12. Köhler $G$, Milstein $C$ : Continuous cultures of fused cells secreting antibody of predefined specificity. Nature 1975, 256:495-497.

13. Raghava GPS, Agrewala JN: Method for determining the affinity of monoclonal antibody using non-competitive ELISA: a computer program. J Immunoassay 1994, 15:115-128.

14. Joseph L: Fleis: Statistical methods for rates \& proportions. 3rd edition. New Jersey, USA: John Wiley \& Sons; 2003.

15. WHO: World malaria report. Geneva, Switzerland: World Health Organization; 2011.

16. Rogerson SJ, Carter R: Severe vivax malaria: newly recognized or rediscovered. PLOS Med 2008, 5:e136.

17. World Health Organization Scientific Group: The biology of malaria parasites. WHO Tech Rep Scr 1987, 743:1-229.

18. Iabal J, Khalid N, Hira PR: Comparison of two commercial assays with expert microscopy for confirmation of symptomatically diagnosed malaria. J Clin Microbiol 2002, 40:4675-4678. doi:10.1128/JCM.40. 12.4675-4678.2002.

19. Ratsimbasoa A, Randriamanantena A, Raherinjafy R, Rasoarilalao N, Ménard D: Which malaria rapid test for Madagascar? Field and laboratory evaluation of three tests and expert microscopy of samples from suspected malaria patients in Madagascar. Am J Trop Med Hyg 2007, 76:481-485

doi:10.1186/1475-2875-12-199

Cite this article as: Dzakah et al:: Plasmodium vivax aldolase-specific monoclonal antibodies and its application in clinical diagnosis of malaria infections in China. Malaria Journal 2013 12:199.

\section{Submit your next manuscript to BioMed Central and take full advantage of:}

- Convenient online submission

- Thorough peer review

- No space constraints or color figure charges

- Immediate publication on acceptance

- Inclusion in PubMed, CAS, Scopus and Google Scholar

- Research which is freely available for redistribution 